\title{
Holstebro Festuge: Re-pensando o Teatro
}

Julia Varley*

Tradução de Andrea Copeliovitch

RESUMO: O artigo de Julia Varley traça a história da Holstebro Festuge, festival promovido pelo Odin Teatret desde 1989. A primeira parte traz um relato de suas memórias acerca de alguns espetáculos no Festival, os quais ocorreram em locais inusuais, promovendo um ambiente mágico à cidade provocado pelo inusitado. Essas apresentações contavam também com a colaboração da comunidade local (como policiais e bombeiros, por exemplo), reduzindo a distância entre os reinos da realidade e da imaginação. A segunda parte traz um histórico das Festuge, com seus efeitos sobre a comunidade. A terceira parte levanta reflexões acerca de como manter o papel social agregador do teatro, sendo o ator considerado um "construtor de relações".

PALAVRAS-CHAVE: Holstebro Festuge, cidade como palco, papel do ator.

ABSTRACT: Julia Varley's article traces the history of Holstebro Festuge, a festival promoted by Odin Teatret since 1989. The first part features an account of her memoirs about some performances at the Festival, which occurred in unusual locations, promoting a magical environment to the city caused by the unexpected. These presentations also had the collaboration of the local community (such as

\footnotetext{
* Julia Varley nasceu em 1954, em Londres, unindo-se ao Odin Teatret em 1976. Morou na Itália, tendo cursado filosofia na Universidade de Milão; nesta mesma cidade, chegou a trabalhar no Teatro do Drago, no Centro Sociale Santa Marta e no Circolo La Comune, ganhando a vida como assistente de produção de filmes. Já participando do Odin Teatret, lecionou em escolas e universidades e sintetizou sua experiência em quatro demonstrações técnicas: $O$ eco do silencio, $O$ irmão morto, Texto, ação, relações e $O$ tapete voador. Desde 1986 participa ativamente no Magdalena Project, que reúne as mulheres do cenário teatral contemporâneo. Desde 1990 participa da organização da ISTA e da University of Eurasian Theatre, instituições dirigidas por Eugenio Barba. É diretora artítica do Transit International Festival de Hostebro e editora do jornal The Open Page, voltado ao trabalho da mulher no teatro. Além de artigos, escreveu os livros: Wind in the West - a novel by a theatre character, Pedras de agua e Uma atriz e suas personagens.
} 
police and firefighters, for example), reducing the distance between the realms of reality and the imagination. The second part brings a history of the Festuge with its effects on the community. The third part raises reflections on how to maintain the social role of the theatre, being the actor considered a "relationship builder".

KEYWORDS: Holstebro Festuge, city as a stage, role of the actor.

\section{Imagens}

Eu estava em turnê em Mar del Plata, Argentina, em 2002. Durante uma palestra eu estava explicando sobre a Festuge, a semana festiva que o Odin Teatret organiza a cada três anos em Holstebro, em colaboração com centenas de instituições locais. Eu falava sobre uma cena do espetáculo "Skibet Bro" que a diretora Kirsten Delholm tinha apresentado no telhado de um supermercado em 1991: "Três caminhões militares cheios de recrutas chegaram inesperadamente. Os soldados estavam de cuecas. O oficial ordenou-lhes que descessem e realizassem uma série de exercícios. Eles tiveram de mudar seus diferentes uniformes - de verão, de inverno, de trabalho, de recreação, de desfile, de batalha - na frente dos espectadores, seguindo o ritmo dado pelo oficial."

Vi as expressões surpresas e incrédulas dos argentinos ao me ouvirem. Tinham o mesmo espanto pintado em seus rostos que os espectadores dinamarqueses tinham na cena original. Continuei a narrar: "Alguns soldados puseram pinturas de camuflagem sobre a pele, prontos para a batalha, outros pintaram feridas falsas em seu corpo antes de se deitarem em macas para serem socorridos. Precisão e eficiência caracterizavam a ação. A alguns metros de distância, um ator indiano de Kathakali, no esplendor de seu traje, sentou-se num banquinho, colocando maquiagem para transformar seu rosto em um demônio. No lado oposto, os personagens do espetáculo de rua do Odin Teatret eram alinhados guiados por Mr. Peanut - a Morte sobre pernas de pau - que, enquanto dançava, fingia cair sobre os soldados feridos".

O espetáculo no telhado do supermercado - uma sucessão de cenas que acompanharam a construção de um navio ligeiramente futurista de inspiração viking - durou ininterruptamente por nove dias e nove noites. Esta é a duração de cada Festuge e de seus numerosos eventos, sejam eles culturais ou municipais religiosos ou seculares, militares ou atléticos, didáticos ou recreativos, políticos ou folclóricos. Um quadro espetacular é criado em torno de ocupações 
que geralmente ocorrem em ambientes separados - fábricas, escolas, escritórios, clubes esportivos - e que muitas vezes passam despercebidos por causa de sua normalidade cotidiana. Colocadas em contextos incomuns, essas atividades tornam-se visíveis e surpreendentes, e os habitantes perplexos ficam curiosos, pois são forçados a reconsiderar o que é familiar a partir de um novo ponto de vista. A cidade se transforma; torna-se imprevisível, mágica.

Este efeito é o resultado da aliança entre o Odin Teatret e as numerosas associações locais que preparam a Festuge por muitos meses. Pode ser tentador pensar que isso acontece porque a Dinamarca é de alguma forma diferente, um país progressista preparado para aceitar imediatamente a desorientação que o teatro pode provocar na ordem eficiente e no pragmatismo da vida cotidiana. Na realidade, a maioria da população de Holstebro protestou contra os políticos que tinham convidado o Odin Teatret a mudarem-se de sua cidade de Oslo, na Noruega. Em 1967, quando os habitantes da cidade viram um programa de televisão dedicado ao Odin Teatret, ficaram chocados com as imagens que não correspondiam à sua ideia de teatro. Muitos anos de trabalho paciente e contínuo foram necessários para mudar essa atitude.

Continuei a explicar a Festuge ao meu público argentino falando de outro espetáculo, esta de 1998, e encenada por Tage Larsen, um ator e diretor do Odin Teatret. Aconteceu no lago de Holstebro. "Os soldados ajudaram-nos a iluminar todo o cenário com bombas de luz. A fumaça vermelha e verde refletida na água dava a impressão de um apocalipse. Enormes bonecos de papel maché, confeccionados nos meses anteriores por crianças de diferentes escolas, flutuavam em jangadas. Canoas e caiaques dançavam ao redor dos bonecos e alguns arqueiros os golpeavam com flechas de fogo. Estátuas de bronze apareciam das chamas e dos restos incinerados. Mergulhadores submarinos arrastaram as estátuas para a praia, onde um guindaste as colocava em um caminhão para levá- las a seu destino final. As estátuas haviam sido compradas pela cidade e a Festuge apresentava-as aos habitantes".

Entre as muitas associações e instituições que contribuem com sua "cultura" e "identidade profissional" para a complexa tapeçaria da Festuge estão os soldados, bombeiros e policiais. Esses funcionários públicos são aliados preciosos no esforço de surpreender os espectadores, de quebrar os preconceitos e hábitos mentais que formamos através da experiência cotidiana. Um evento incluiu cerca de dez policiais realizando sua sinalização rodoviária acompanhados por uma orquestra; os movimentos amplos e precisos de seus braços, conduzidos 
em uníssono com a música, davam o efeito de um balé. Outra vez, colocamos um enorme rosto de papel machê no ponto mais alto da escada de um caminhão de bombeiros. Da boca do boneco gigante, um fluxo de água regava um casal de idosos que dançava embaixo.

Eu apresentei mais um espetáculo da Festuge para meus céticos ouvintes. Esta aconteceu em 2001 e a maravilha que eu senti ao participar ainda estava viva em mim enquanto eu narrava em Mar del Plata. "A apresentação final foi orquestrada por Tage Larsen como uma festa de casamento camponesa, acompanhada por danças de balé e folclore, por jovens de diferentes clubes de karatê e taekwondo lutando, e por pilotos escoltando o carro da noiva em meio a fogos de artifício. O palco era um campo amplo entre duas colinas à saída de Holstebro. Alguns soldados em uniformes de diferentes épocas apareceram, seguidos por jipes modernos e um tanque. O espaço se encheu de soldados correndo em diferentes direções, atirando contra um inimigo imaginário e rolando no chão, fingindo terem sido atingidos. Foi uma verdadeira manobra militar organizada com o comandante do quartel e, no silêncio após a batalha, uma família de imigrantes e uma dinamarquesa, com dois filhos cada, caminharam lentamente para o centro do campo deserto. Sentaram-se perto uma da outra para fazer um piquenique, e à sua volta surgiram as cabeças de crianças enterradas até o pescoço, que cantavam um salmo dinamarquês, enquanto Mr. Peanut - Morte - caminhava ao fundo".

Compreendi que era difícil para o meu público argentino, com a memória da sua ditadura militar ainda muito viva, acreditar nas minhas palavras. Mas tudo era verdade. Durante as nove Festuge que organizamos desde 1989, o teatro reuniu os mais impensáveis agrupamentos de pessoas, ofícios e organizações, reduzindo a distância entre os reinos da realidade e da imaginação. Naquele dia, em Mar del Plata, perante a incredulidade daqueles que me ouviam, decidi convidar atores de todo o mundo para um workshop destinado a apresentá-los a nossos projetos e atividades em Holstebro. O Odin Teatret é conhecido como um laboratório de teatro. Nossos espetáculos, prática pedagógica e pesquisa em antropologia teatral são familiares para estudantes de teatro e profissionais, mas poucos estão cientes de nossos empreendimentos locais e do trabalho que desenvolvemos como um laboratório cultural. Eu queria demonstrar aos participantes que o impossível pode ser alcançado quando atores tecem relacionamentos duradouros com sua comunidade. $O$ teatro pode superar preconceitos e inibições, e instigar energias quiescentes através da partilha de um interesse comum. 
Eu queria que outros experimentassem como um concerto pode acontecer em uma igreja luterana em que hebreus, muçulmanos, católicos, protestantes, animistas, devotos do candomblé afro-brasileiro, budistas e hindus cantam para se comunicar com seus próprios deuses, todos sob o mesmo teto. Ou como roqueiros com suas poderosas motocicletas, casacos de couro preto e tatuagens, podem mergulhar em um quadrado que acabou de ser desinfetado pela espuma dos bombeiros, cada um carregando uma estudante colegial loira no banco de trás. Eu queria que os céticos sentissem o súbito efeito dos motores das motocicletas simultaneamente desligados enquanto uma criança toca um adagio clássico no violino, que por sua vez desvanece lentamente em meio às sirenes de carros policiais que convergem na praça vindos de toda a cidade, e em meio aos sinos das igrejas que anunciam a chegada de caçadores acompanhados por cães e uma fanfarra de chifres.

Organizei a oficina para trinta atores e chamei-o de "Ageless" (sem idade). O primeiro foi realizado para a Festuge de 2005. Eu tive ajuda de Augusto Omolu, o performer afro-brasileiro do Odin Teatret, e de Deborah Hunt, uma experiente criadora de máscaras, marionetes e enormes fantoches, estabelecida em Porto Rico. Para ter uma experiência direta, cada participante foi responsável por organizar um evento em um ambiente particular ao redor da cidade. Um ator de Hong Kong escolheu a agência de correios. Carteiros distribuem cartas; em contraste, o ator decidiu escrever e entregar pessoalmente um cartão postal a cada um deles. Durante toda a noite, ele pintou pinturas a óleo em formato de cartão postal, às quais acrescentou selos, e às cinco da manhã chegamos ao correio com um desfile de máscaras e canções. Os cinco carteiros que estavam no trabalho ficaram surpresos. Ao receberem seus cartões postais, agradeceram aos estrangeiros com olhos brilhantes. Outro ator, um italiano, preparou uma visita à padaria. Ele queria oferecer-lhes um bom expresso para que pudessem saborear a diferença entre o café italiano e o dinamarquês. Às quatro da manhã, quando começamos a amassar o pão, os personagens mascarados serviram café e uma canção a alguns dos padeiros da cidade. Em troca, recebemos pães quentes para levar conosco para a nossa próxima visita: café da manhã em um lar de idosos.

Para cada Festuge, fazemos um desfile noturno. Um ano, partimos à meia-noite do canto do parque, onde ficam as estátuas de Kai K. Nielsen e Jens Johansen, o prefeito e o administrador da cidade que convidaram o Odin Teatret para Holstebro em 1966. Iluminados por velas, saudamos as figuras de pedra com um poema e seguimos ao longo do rio, depositando 
pequenos barcos de papel com luzes na água. Não havia absolutamente ninguém ao redor, mas ainda assim ao longo do caminho algumas pessoas nos viram de suas janelas ou de um táxi de passagem. É assim que se cria a lenda de uma cidade animada por seres estranhos que aparecem em todos os momentos do dia e da noite. Um político municipal chegou à sua janela naquela noite e viu pessoas subindo no parapeito da ponte, prontas para saltar para o rio. Seu primeiro impulso foi chamar a polícia; depois se lembrou do Odin Teatret e se sentiu tranquilizado. Ele sabia de nós, embora só compreendesse verdadeiramente as consequências do que fazemos durante uma viagem ao Brasil, quando alguém Ihe disse: "Ah, você vem da Dinamarca, o país de Odin Teatret!"

Pelo menos uma vez a cada Festuge, fazemos uma visita ao cemitério. Às vezes apenas um personagem entra para deixar uma flor e soltar um balão, outras vezes pequenos grupos de espectadores seguem diferentes contadores de histórias para ouvir sobre a vida daqueles que descansam sob as lápides; outros ainda fazem serenata para os mortos.

Um ano decidimos ir à maternidade do nosso hospital. Os trajes de papel dos grandes fantoches usados pelos atores de Ageless produziam um leve sussurro que acompanhava o suave pandeiro, dando ritmo ao passo de nossa procissão. Paramos no corredor enquanto um de nós entraria em um quarto para oferecer uma semente a cada nova família. Mais tarde, as enfermeiras telefonaram para compartilhar suas emoções e as dos pais. Desde então, eles sempre nos convidam para voltar à ala. Depois, também visitamos o hospital psiquiátrico, onde temos o cuidado de criar uma relação de intimidade com os espectadores que mantém uma distância respeitosa, permitindo que se sintam seguros.

Para cada Festuge há um número infinito de anedotas para lembrar: no início da manhã, à chegada dos trens, à entrada das escolas, nas cafeterias das fábricas, nos jardins, nos museus, ao longo da rua de pedestres no centro da cidade ou nas estradas vazias de um subúrbio... Imagens passam pela minha mente: de edifícios feitos de fardos de palha que são rearranjados à noite para criar um coliseu ou uma pirâmide; de montanhistas que escalam o campanário da igreja; de atores peruanos disfarçados de diabos que correm para o lago rufando e chapinhando na água para chegar à ilha onde uma dançarina indiana é salvaguardada por um grupo de elegantes atores sobre pernas de pau; do enterro de um barco no parque com a ajuda de uma escavadeira municipal; da construção de uma ponte sobre o rio que separa duas aldeias de diferentes províncias; do desfile de balineses e jovens punks que invade um 
supermercado; da aluna da escola de balé que faz piruetas em um fardo de palha levantado por um trator; da exposição fotográfica de casais mistos de Holstebro exibida nas vitrines da rua principal; da procissão nupcial do castor gigante e pinguim saudados pelo paraquedista vestido de noiva; da dançarina de flamenco que dialoga com o som de cascos de cavalo...

O que torna a Festuge especial é o envolvimento maciço de vários setores da população durante nove dias e noites. As instituições, associações e indivíduos aceitam a interferência do teatro em suas programações diárias como um estímulo para os seus campos específicos e uma confirmação do seu valor profissional ou cultural. Mas isso também acontece porque as pessoas gostam de estar ativas quando se sentem inspiradas. Elas gostam da disponibilidade colaborativa de pessoas e meios desconhecidos. São tocadas e transformadas por impressões estéticas, cenas poéticas, imagens pungentes e encontros diretos com artistas e outras pessoas cativantes. Em dinamarquês "festuge" significa literalmente "semana festiva". Estas semanas são organizadas em outras cidades dinamarquesas também, mas a Holstebro Festuge é diferente porque ela faz mais do que apenas oferecer uma sequência de espetáculos, concertos, exposições e palestras. É a radiografia de uma variedade de culturas que estão ativas em um lugar particular - nossa cidade - e é a consequência de meio século de parceria entre o Odin Teatret e os cidadãos de Holstebro. A Holstebro Festuge não prova que os moradores de uma cidade podem unir-se espontaneamente em colaboração fraterna e aceitação mútua. A realidade é que os poderes de separação ainda florescem em nossa sociedade. Podemos lutar contra essa tendência com um planejamento completo e anos de experiência. O exército, comerciantes, policiais, professores, bombeiros, sacerdotes, pacifistas, estudantes, idosos, médicos, imigrantes, agricultores e outros - todos eles participam da Festuge, para participar de um mundo que pelo menos por alguns dias se deixa guiar pela imaginação e pelas emoções. Conforme concebida e desenvolvida pelo Odin Teatret, a Festuge é um laboratório social baseado nas trocas culturais - um escambo tde bens ou serviços por qualquer coisa menos dinheiro. Os interesses e benefícios mútuos dos participantes são o seu motor. Os atores desempenham o papel de negociadores, de construtores conhecedores de diálogos performativos temporários entre partidos que normalmente se ignoram.

Após 25 anos de contatos feitos para planejar a Festuge, Holstebro mudou. Nas palavras do nosso prefeito atual, H. C. Østerby, é uma cidade de grande colaboração entre grupos díspares e mínimos conflitos étnicos: "O Odin Teatret faz espetáculos que quase não entendemos, 
mas gradualmente começamos a receber outras imagens e percepções, porque agora o teatro criou uma identidade. Não há dúvida de que o fato de ter o Odin Teatret teve um enorme impacto em romper as barreiras culturais quando se trata de compreensão do cidadão médio de outras culturas. Embora em Holstebro termos a Trekantsområdet onde muitos imigrantes vivem, não temos tido "problemas de gueto" como em várias outras cidades. O Odin Teatret ajudou a abrir os olhos das pessoas ao que é estrangeiro, e Holstebro não é mais uma pequena comunidade fechada".

\section{História}

Lembro-me da sala vermelha do Odin Teatret cheia de espectadores. Nós tínhamos acabado de terminar o espetáculo "O Milhão" e estávamos entregando um prêmio ao escritor alemão Henrich Böll em nome de Jens Bjørnboe - o autor norueguês que apoiou o Odin Teatret durante os primeiros anos em Oslo. Era 1989 e nós celebrávamos o $25^{\circ}$ aniversário do Odin Teatret. Em vez de nos dar flores ou garrafas de vinho, tínhamos pedido às instituições culturais de Holstebro para organizar um evento com um artista estrangeiro estabelecido na Dinamarca, uma descrição que caracteriza com precisão muitos dos membros do Odin Teatret. Eram anos xenófobos na Europa, período em que alguns partidos políticos exigiam a expulsão de imigrantes e a abolição dos subsídios das artes. Com nossa festa queríamos celebrar o exemplo de Holstebro, a cidade que acolheu um grupo estrangeiro como seu teatro municipal, e rememorar os políticos daquele distante ano de 1966 que nos defenderam contra a cólera dos cidadãos que não conseguiam ver a utilidade de financiar um laboratório de teatro. Depois de 25 anos, o Odin Teatret tornou-se um exemplo da cultura dinamarquesa.

Casos semelhantes podem ser encontrados em outras áreas artísticas: na ópera, ballet clássico e moderno, literatura, escultura, cinema, design, moda. Muita arte dinamarquesa tem sido criada por deslocados de guerra, refugiados, imigrantes, estrangeiros atraídos para a Dinamarca por dinheiro ou amor. Então a biblioteca da cidade, a escola de música, o museu, o clube de jazz e o grande teatro de Holstebro, convidaram artistas dinamarqueses de origem estrangeira para celebrar o Odin Teatret.

Nós estruturamos essas atividades em um programa que chamamos "Estes, nós os acolhemos" e oferecemos a Holstebro como agradecimento por nos ter sediado e apoiado durante 


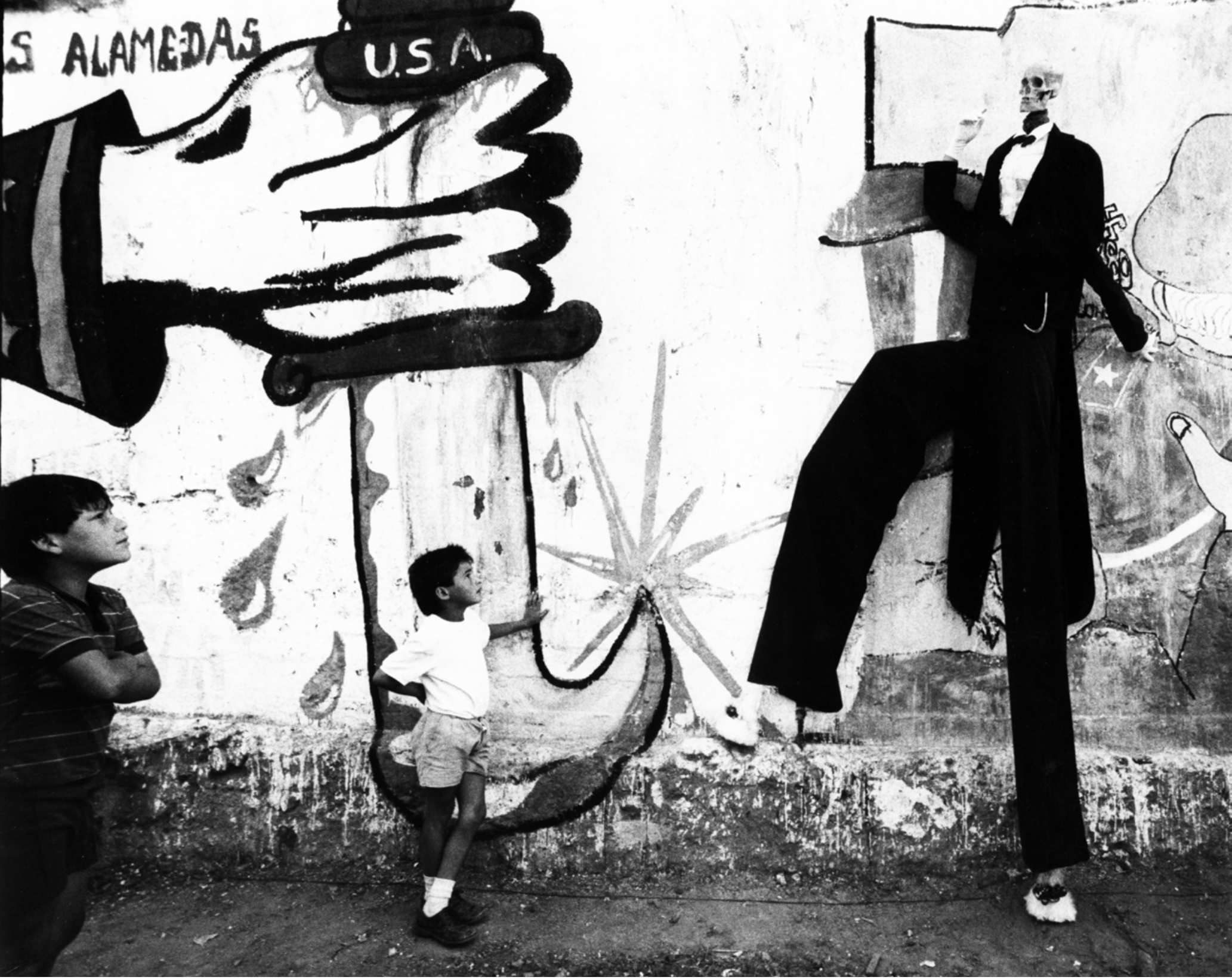

Mr. Peanut in a slum near Santiago de Chile

Fotografia: Tony D'Urso /

Fonte: http://odinteatret.dk/ 
tanto tempo. Entre os convidados estavam o diretor musical Francesco Cristofoli (filho de um pedreiro italiano), o cineasta Gabriel Axel (com seu filme de "A festa de Babette"), o cantor de ópera Aage Haugland (norueguês), e os solistas Michaela Fukacova (exilada Checa) e Anton kontra (exilado húngaro).

Oficialmente, a celebração de 1989 é considerada a primeira Holstebro Festuge. A iniciativa que se materializou a partir da celebração do nosso $25^{\circ}$ aniversário foi, na realidade, apenas uma das sementes da ideia do que viria a tornar-se o que é hoje a Festuge. Outra prática que contribuiu para formar o perfil e a dinâmica da futura Festuge foi a "troca", um intercambio de manifestações culturais que o Odin Teatret vem praticando desde 1974.

A verdadeira Holstebro Festuge, com sua rede de colaborações resultantes da troca entre os diferentes setores da população, tem suas origens em 1991, quando adotamos o lema "culturas sem fronteiras".

No ano anterior, em 1990, Niels Højlund, um político influente ativo na vida cultural dinamarquesa, convidou Eugenio Barba, diretor do Odin Teatret, para fazer um programa de televisão. Eugenio Barba recusou a oferta, mas apresentou uma contraproposta para o Fundo de Cultura, do qual Niels Højlund era o presidente: um projeto chamado "Holstebro Festuge". Um dos objetivos do Fundo era a colaboração entre artistas profissionais e amadores. O Odin Teatret recebeu uma soma considerável: 850.000 coroas dinamarquesas (cerca de 115.000 euros hoje). Como já aconteceu outras vezes, o apoio financeiro nos obrigou a ser criativos e a converter projetos abstratos em resultados concretos.

Naqueles anos, falava-se muito da comemoração iminente do $500^{\circ}$ aniversário da descoberta das Américas. Os nossos amigos latino-americanos reagiram polemicamente à visão eurocêntrica de uma tal celebração. Mas o Odin Teatret inspirou-se em Cristovão Colombo para o tema da Festuge, intitulado "O Colombo Dinamarquês." A diferença entre 1989 e esta vez é que inverteu-se o sentido da viagem. Concentramo-nos no povo dinamarquês que partia para terras estrangeiras próximas e distantes, estabelecendo-se no estrangeiro ou trazendo para casa as impressões recolhidas durante suas visitas internacionais: missionários, exploradores, comerciantes, médicos, antropólogos, soldados e artistas.

Usando o subsídio do Fundo de Cultura, Eugenio decidiu dar 450.000 coroas dinamarquesas para Kirsten Delholm, uma diretora estabelecida em Copenhaguem, cuja visão estética é 
radicalmente diferente da de Odin Teatret. Ela deveria preparar um espetáculo no lago próximo de Holstebro e envolver os habitantes da cidade. Kirsten preferiu o telhado do estacionamento de um supermercado. Ela criou "Skibet Bro" lá, com a participação de numerosas associações locais e do Odin Teatret, que a cada meia-noite apresentava uma cena do espetáculo "Fantasmas de Marinheiros".

Durante nove dias e nove noites, sem interrupção, Kirsten e um grupo de voluntários construiu um barco em torno do qual, a cada quatro horas, as cenas eram desenvolvidas tal qual descrevi para os argentinos, em Mar del Plata. O navio foi leiloado no último dia e comprado pelo Odin Teatret que passou a enterrá-lo no parque de Holstebro durante o espetáculo de encerramento da Festuge. "Caminhos d'água" foi o título sob o qual foram montados mais de 100 espetáculos, happenings, concertos, palestras e desfiles. Realizado por associações da cidade juntamente com o Hotel Proforma (Copenhaguem, Dinamarca), Teatro Tascabile di Bergamo (Itália), e Akadenwa (Aarhus, Dinamarca).

Depois de "Estes, nós os acolhemos" (23-30 novembro de 1989), e de "O Colombo Dinamarquês" (6-15 de setembro de 1991), para cada Festuge nós escolhemos um título e um tema para nos guiar na seleção dos artistas convidados, e que serve como inspiração para as outras instituições da cidade. Exemplos incluem "Casamentos Mistos - Knud Rasmussen" (412 de setembro de 1993), "No Fim do Mundo" (29 de agosto a 6 de setembro, 1998), "A mordida do Tempo - o passado, o efêmero e o amanhã" (25 de agosto a 02 de setembro, 2001), "O esplendor das eras" (27 agosto a 4 setembro de junho, 2005), "Luz e escuridão" (7-15 de junho de 2008), "Histórias de amor" (4-12, de junho, 2011) "Rostos do futuro - Fantasmas e ficções" (14-22 de junho, 2014). O Festuge previsto para 2017 é intitulado "The Wild West roots and shoots: Re /Think" ("O Oeste Selvagem - raízes e disparos: Re / Pense").

O tema "Casamentos Mistos - Knud Rasmussen" (1993) era para ser interpretado no sentido literal e simbólico: os casamentos entre pessoas de diferentes nacionalidades (como o exemplo do explorador do Ártico Knud Rasmussen de origem dinamarquesa e da Groenlândia), ou a união de formas artísticas diferentes, ou entre cultura e comércio, velhos e jovens, natureza e tecnologia. Um dos objetivos centrais era o encontro dos opostos. O espetáculo "Até que a morte nos separe" durou toda a Festuge. Foi feito pelo Odin Teatret com a participação da dançarina indiana Sanjukta Panigrahi e seus músicos, do grupo peruano Yuyachkani e do Teatro 
Tascabile di Bergamo (Itália). O compositor indiano Ragunath Panigrahi e o dinamarquês Frans Winther compuseram separadamente duas óperas com base em "Shakuntala", o texto clássico indiano de Kalidasa. Durante sete dias, estes foram apresentados, em episódios intercalados, com atores / dançarinos da Índia, Peru, Itália e do Odin Teatret, juntamente com cantores de ópera dinamarqueses e mais de 200 jovens músicos da Escola de Música de Holstebro. O tema deste Festuge inspirou a organização de um concurso para o cachorro bastardo mais bonito e para o melhor animal inventado pelas crianças em idade escolar: um hipofante, um cavalássaro, um leocobra...

"No fim do mundo" (1998) aludiu às dimensões geográficas e temporais. O título foi sugerido pelo fim iminente do milênio, mas também pela região onde está situada Holstebro, distante da capital, em uma paisagem devorada pelo mar e chicoteada pelo vento. O tema referia-se a tempo e espaço: a fronteira do mundo que conhecemos o fim de uma era e a chegada de algo novo. Tage Larsen dirigiu um espetáculo de quatro dias que ele preparou com crianças de diferentes escolas durante o inverno e a primavera. Ele a apresentou em um palco sobre o lago, com a ajuda de mergulhadores, soldados, canoístas, caiaqueiros, arqueiros e bailarinos. O Teatro Taller de Colombia, o escultor Hans Krull e suas estátuas estavam entre os convidados, juntamente com dançarinos, atores e músicos do Brasil, Índia, Japão, Bali e do Odin Teatret. Os últimos foram os componentes do Theatrum Mundi, o grupo do ISTA (International School of Theatre Anthropology) que apresentou o espetáculo "A Ilha dos Labirintos" dirigido por Eugenio Barba.

"A mordida do tempo - o passado, o efêmero e amanhã" (2001) referia-se a um horizonte de memória e imaginação. Convidamos o Teatro Potlach (Itália), juntamente com mais de 50 artistas europeus, incluindo cantores de ópera, dançarinos de tango, um quarteto de saxofones e uma orquestra de acordeão. O Grupo Bagunçaço Cultural do Brasil participou com seus 25 meninos de rua de Salvador dirigidos pelo músico Wilson Café. Tage Larsen do Odin Teatret, Pino de Buduo da Itália e Paulo Dourado do Brasil colaboraram para dirigir um espetáculo em três atos, que aconteceu em diferentes partes da cidade, com a participação de escolas de equitação, do regimento do dragão, de tanques do exército, do clube de carros antigos, de dançarinos folclóricos e de clubes desportivos. Frans Winther compôs e encenou "O tempo da água - A Luz do Dia e do Adeus", inserindo no espetáculo uma escultura cinética de Kirsten Justesen e textos do poeta Thomas Boberg. 
Para a Festuge "O esplendor da idade" (2005), organizei a primeira oficina "Ageless" (Sem Idade) com Deborah Hunt, Augusto Omolu, Sally Rodwell e Hisako Miura. O Teatro Tascabile di Bergamo, Teatro Bilico (Itália) e Teatro Atalaya (Espanha) mantiveram a tradição de apresentações durante todo o Festuge. Sabíamos desde a Festuge de 1998 que, apesar da chuva, os espectadores seguiriam cada episódio em números cada vez maiores. Em uma manhã de sábado, no horário de pico das lojas, todos os grupos compuseram um espetáculo itinerante em que as idades eram marcadas pelas estações de uma árvore: sem frutos, em floração e finalmente dando frutos. A árvore era levada por dois corvos que ajudavam Mr. Peanut na mudança cerimonial de trajes do vermelho para o preto para o branco. Todos os artistas trocavam a cor de suas roupas, seu comportamento e o acompanhamento musical. Kai Bredholt do Odin Teatret organizou uma Festa da Colheita, envolvendo aldeias inteiras na construção de animais de palha e danças tradicionais. Frans Winther compôs e dirigiu a ópera contemporânea "Ezra Pound", com a participação do poeta Peter Laugesen.

"Luz e escuridão" (2008) retomou os contrastes entre as cores, grupos étnicos, regras, horários, eventos, inserindo-os em histórias clássicas e contemporâneas. "O casamento de Medeia", dirigido por Eugenio Barba, era uma procissão nupcial das famílias de Jasão e Medeia em que as famílias se moviam lentamente pelas ruas durante todo o dia. Atores do Odin Teatret, 33 músicos balineses e dançarinos do Pura Desa Gambuh, os brasileiros Augusto Omolu e Cleber da Paixão, e 35 jovens atores de 21 nacionalidades, todos dançavam e cantavam enquanto seguiam um barco de pesca balinês colorido. O barco era um símbolo tangível da chegada dos estrangeiros e, cercado por aquela festividade alegre, constituía o centro em torno do qual os fatos precedentes e posteriores ao casamento de Medeia e Jasão seriam narrados. "A escuridão brilhante do amor", dirigida e composta por Frans Winther, com a participação de mais de cem atores amadores locais, incluindo um pizzaiolo curdo, contava a fábula de uma mãe dinamarquesa sofisticada e progressista que se recusa a aceitar o amor de seu filho por uma menina estrangeira que usava o véu. Um Cabaré noturno oferecia a possibilidade de ouvir música, canções e poemas realizados pelos artistas convidados, regados a cerveja e vinho. Uma longa procissão em preto e branco com mais de 200 participantes, acompanhada por várias orquestras, invadia a rua de pedestres para o tradicional espetáculo itinerante de sábado com cenas cheias de esperança e incerteza. 
Eros nutre os valores fundamentais da vida: amizade, ternura, solidariedade e amor. O oitavo Festuge intitulado "Histórias de amor» (2011) foi um encontro com o poder de Eros. O Teatro Potlach (Itália) apresentou "Cidades Invisíveis", um espetáculo site-specific e multimídia que utilizava a totalidade das instalações físicas do Odin Teatret. Milhares de espectadores passavam pelos corredores, quartos, escritórios e lojas de nosso teatro transformados para a Festuge pelos artistas convidados e por mais de 150 membros de associações da cidade: os clubes de xadrez, canoagem, tricô e taekondo, a orquestra sinfônica, escolas de balé e de música, dançarinas do ventre, músicos e atores amadores, entre muitos outros. O Teatro Tascabile de Bergamo voltou com os espetáculos "Valse" e "Albatri" tão apreciados pelos habitantes de Holstebro, mas também com seu novo "Storie di Montecchi e Capuleti". Uma caravana de poesia visitou as aldeias ao redor de Holstebro. Era formada pelo poeta Abdallah Zrika e o cantor Touria Hadraoui de Marrocos, o poeta Thomas Boberg e o músico Anders Allentoft da Dinamarca, o percussionista francês Francesco Agnello, o músico alemão Uta Motz e a atriz Iben Nagel Rasmussen do Odin Teatret. Frans Winther compôs a música e dirigiu Down by the River Saloon no Musikteatret de Holstebro, um conto sobre o conflito entre os jovens de uma escola. Mais de uma centena de bailarinos, cantores, estudantes e músicos locais contaram a história alternando diálogos de rap, hip-hop e dança afro-brasileira, ballet e teatro balinês, com I Wayan Bawa . O grupo internacional Jasonites, originado da família de Jasão na Festuge anterior, preparou uma versão em quadrinhos de histórias de amor de Shakespeare, enquanto os participantes das duas oficinas "Ageless" e "Dance of Love" seguiam um gigantesco par de noivos: um pinguim de três metros de altura e um castor em papel-maché feitos por Deborah Hunt. O Piccolo Teatro de Pontedera, com doze atores e músicos em bicicleta, apresentou "Loving Lisbon", e Kai Bredholt do Odin Teatret reuniu coelhos, cavalos, ovelhas e pastores, idosos do Centro Sønderland e esculturas de anjo com rodas feitas pelo artista Marit Benthe Norheim em sua Global Village construída com fardos de palha na frente da igreja, no centro da cidade.

Em nossa mais recente Festuge, "Rostos do futuro - Fantasmas e Ficções" (2014), muitos dos artistas convidados são crianças e adolescentes de Bali, Quênia, Brasil, Itália e Índia. O Odin Teatret imagina um futuro que se expressa com disciplina criativa: crianças do leste, oeste, norte e sul mostraram o engajamento e a alegria de seu ofício artístico com teatro, circo, dança e música. As companias convidadas foram hospedadas por escolas de Holstebro e da 
região. Além de se envolverem em espetáculos, participaram de intercâmbios culturais com crianças, professores e pais locais que utilizaram suas próprias histórias e música, máscaras e cenas de teatro previamente preparadas em colaboração com oTeatro Potlach, Deborah Hunt, Jasonites, Parvathy Baul, Carolina Pizarro, Guido Accascina e atores do Odin Teatret. Ao final do Festuge de 2014, o Odin Teatret comemorou seu 50 aniversário com uma trilogia intitulada "Medindo o Tempo". Três espetáculos diferentes especialmente preparados por Eugenio Barba foram apresentados apenas uma vez em 22 de junho, 2014: "Se o trigo não morre" (O Futuro), "Claro enigma" (O Passado) e "O segredo de Alexandre" (O Presente).

As atividades de "The Wild West: Roots and Shoots. Re /Think" (2017) focarão na selvageria da natureza. O contato com o mundo natural é representado por cavalos e sua interação com a civilização industrial e tecnológica, evidenciada pelos tratores que aparecem no horizonte prontos para dançar juntos, ao ouvir concertos de tiros de fuzil e fogos de artifício. As aldeias vão se preparar para receber e hospedar caravanas de artistas a cavalo. Os cavalos serão a estrutura e os colaboradores de muitas transformances - eles serão os meios de transporte e o gatilho poético para diversas iniciativas, como exposições de pintura e sessões terapêuticas. O som rítmico de seus cascos será acompanhado pelo barulho de motocicletas Harley Davidson fazendo-nos repensar o nosso sentido de tempo e os ritmos que nos permitem apreciar a vantagem da velocidade em nossa era tecnológica. As raízes (roots) são a tradição e os disparos (shoots) do futuro: ambos são necessários para re-pensar o nosso presente através da interferência galopante da Festuge.

A abertura de cada Festuge acontece no sábado, ao meio-dia, na praça da Câmara Municipal. É usual que o prefeito - independente de sua filiação política - faça uma aparição teatral antes da palestra de abertura. Se um prefeito recém-eleito hesita quando confrontado com as nossas propostas, basta lembrar-Ihe do exemplo dos prefeitos anteriores. Em "O Cristovão Colombo Dinamarquês", o prefeito ficou escondido dentro de um ovo de papel-mâché enorme levantado por um guindaste, saindo do telhado da câmara municipal para ser depositado entre os espectadores. O prefeito quebrou o ovo, saiu e falou. Em "Casamentos mistos", os padeiros de Holstebro tinham preparado um bolo de casamento gigantesco do qual o prefeito emergia de repente. Após seu discurso, ele ofereceu uma fatia de bolo a todos os casais mistos da cidade que tinham sido especialmente convidados, e depois para o resto dos habitantes. Em "Luz e escuridão", o prefeito estava vestido como um espantalho no meio da praça transformada por 


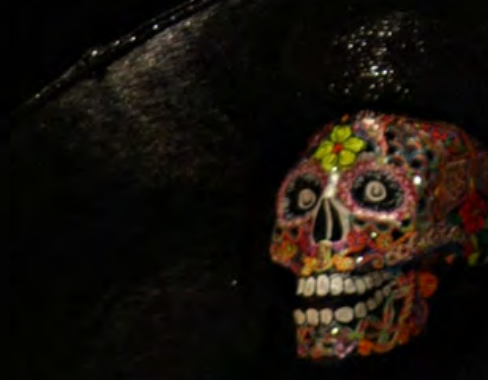

FIIIIIG

- Dana face aniss Ryanter in opposing
incese

Ave Maria

Fotografia: Rina Skeel

Fonte: http://odinteatret.dk/ 
centenas de fardos de palha. Em "Histórias de amor", ele fez a sua entrada em bicicleta também com a sua esposa. Um senso de humor e auto-ironia pertencem à tradição criada pela Festuge. Como Kathrine Winkelhorn escreve: "Holstebro Festuge abre as fronteiras entre as pessoas, mesmo autoridades como o exército e a polícia se envolvem para desempenhar um novo papel. Como disse o chefe de polícia, nós prendemos um urso polar que estava atirando com uma pistola de água e o acorrentamos na rua de pedestres de Holstebro".

O espetáculo de encerramento da Festuge tem lugar no parque de Holstebro. No domingo de manhã muitas famílias vêm, sentam-se no gramado e olham para o monte onde, em 1991, o barco de "Skibet Bro" foi enterrado e uma árvore plantada no topo. Mas o espetáculo surpreende: começa de costas para os espectadores virada para o lago onde patinhos cercam a pequena ilha em que Sanjukta Panigrahi dançou em 1993. As árvores das proximidades foram cobertas de dourado. Figuras de teatro aparecem vindas do estacionamento, do cemitério, do bosque, do hospital para os palcos ao ar livre. Certa vez o Mr. Peanut - a Morte - veio vestido de noiva montado a cavalo. Outra vez cinquenta atores do Theatrum Mundi fizeram uma procissão seguindo acrobatas colombianos sobre pernas de pau. Uma vez um mar de pano branco cobria o gramado e os atores; outra vez, fogos de artifício puseram o lago em chamas enquanto eles, os gigantes de papel machê, estavam queimando e um par de amantes se perseguia mutuamente rolando na água. Ao final do espetáculo, os espectadores deveriam olhar para cima. Uma vez que um pequeno barco seguido por um rastro de rosas vermelhas voava para o céu; outra vez, um cavalo azul levantou do chão como um pássaro. Concluímos com a escrita que também desaparece entre as nuvens: “Vamos ver uns aos outros na próxima Festuge". Esta mensagem que voa para longe deixando um súbito sentimento de saudade dos dias que acabaram de passar.

\section{Reflexões}

Hoje visões artísticas e justificativas culturais não são suficientes para provar a significância do teatro em nossa sociedade. A credibilidade do teatro reside em sua capacidade de cativar as várias camadas da população que são indiferentes às suas expressões e manufatura artística. Isso só pode ser alcançado através de um re-pensamento do know-how do ator e de seus objetivos em relação a uma simples pergunta: como pode o nosso ofício ajudar a gerar relações entre os indivíduos que são ou que se tornaram estrangeiros uns aos outros? 
Ministros e políticos da cultura consideram a expressão teatral uma arte. Eles têm razão: todos nós temos que dar o nosso máximo para manter a excelência artística do nosso ofício. Ao mesmo tempo, é inegável que hoje o valor do teatro também resida em sua capacidade de criar raízes e encontrar novos propósitos tanto nos lados iluminados quanto obscuros de nossa sociedade: em creches e prisões, em bairros residenciais e casas populares, hospitais psiquiátricos e lares de idosos, entre jovens desempregados e guetos étnicos, ao redor de igrejas quase vazias e discotecas cheias demais, em fazendas isoladas, fábricas abandonadas e estaleiros desmontados, bem como em shoppings centers lotados, em cidades-fantasma periféricas e em frenéticos centros urbanos. Nesses lugares o teatro nunca foi uma necessidade urgente ou uma exigência imperativa. Re-pensar significa encontrar uma maneira de despertar tal necessidade ou demanda. O ofício teatral já tem trabalhado muitos procedimentos, dispositivos e processos que assumiram muitos rótulos: teatro social ou aplicado, teatro comunitário, teatro de reciprocidade. O que mais podemos fazer?

O ator é um especialista na construção de relacionamentos: com o passado e o presente, com um texto, consigo mesmo, com os espectadores, com vários tipos de espaço - espaço interno pessoal, espaço geométrico, cultural e social. Os atores do Odin Teatret usam essa especialidade em situações fora do âmbito artístico de um espetáculo, aplicando sua experiência como catalisadores em outros tipos de interações. O objetivo não é a criação de um espetáculo a ser julgado como uma obra artística, mas um ato de transformação da participação e de intercâmbio mútuo entre vários setores de uma comunidade. Essas interações permitem aos participantes expressar sua diversidade, que é tanto sua maior força quanto o principal fator que os mantém separados.

Durante uma Festuge, os habitantes da nossa cidade não são apenas uma audiência potencial ou uma entidade sociológica. Eles são indivíduos com biografias específicas, expectativas e interesses. Somente apelando-se ao orgulho que sentem por seus antecedentes pessoais, e tornando-os conscientes do quanto isso é vantajoso para eles, é possível gerar uma situação de troca coletiva: a troca orientada para o processo de manifestações culturais através de canções, danças, contação de histórias e contos biográficos, exemplos de sua própria tradição culinária, jogos e mesmo simulacros de cerimônias como casamentos. 
Desde 1974 Odin Teatret tem praticado trocas, intercambiando cenas de seus espetáculos por manifestações culturais de diferentes locais. As trocas nunca foram feitas como situações para inspirar os atores, ou como oportunidades de aprender com pessoas de culturas estrangeiras, mas como um encontro que define diferentes identidades, mostrando-as uns aos outros. A experiência nos ensinou isso. A troca deve basear-se no acordo e relevância mútua, já que ninguém está instintivamente interessado em trocar mercadorias culturais com todos os esforços e tempo que isso requer. É a necessidade e a vantagem - e não considerações estéticas ou boas intenções - que determinam que a gente troque um quilo de batatas de nosso próprio jardim pela competência do nosso vizinho em consertar um problema do nosso carro.

A utilização do princípio da troca pelo Odin Teatret em diversos países e configurações sócioculturais nos ensinou que o fator-chave para iniciar suas dinâmicas e alcançar o sucesso é um indivíduo: um homem, uma mulher e, muito raramente, um pequeno grupo de pessoas. Os interesses culturais, políticos, terapêuticos, didáticos, profissionais, étnicos ou comerciais desses indivíduos encontram na proposta de troca uma ferramenta para a realização de seus planos, desejos ou anseios. A variedade de formas de escambo e a flexibilidade de suas estruturas 'dramatúrgicas' pode ser adaptada à conveniência dos seus propósitos. Desta forma um indivíduo é incitado a motivar os outros e pôr em marcha iniciativas em seu ambiente de trabalho ou de residência - uma fábrica, um hospital, um bairro ou até mesmo uma aldeia inteira. Os atores de teatro tornam-se aliados importantes para seus objetivos. Esses aliados são qualificados para atuar e entreter, mas também para reunir pessoas que normalmente nunca se encontrariam. Eles são bons em inventar e estruturar incríveis combinações cerimoniais ou "performativas".

Portanto, a primeira grande dificuldade para realizar uma troca está em detectar os indivíduos nos vários setores da comunidade que podem ser convencidos dos benefícios de tal iniciativa, tanto para si, ou para o que eles representam como para seu ambiente em geral. A primeira tarefa dos atores é encontrar os rebeldes, os impacientes e os solitários, aqueles que sonham com uma iniciativa ou aqueles dispostos a empenhar-se, em suma aqueles que irão fomentar a troca. A intuição dos atores se manifesta também na sua capacidade de detectar as pessoas certas e, em seguida, ajudar esses indivíduos a realizarem na prática um re-pensamento da teia de relações em que operam diariamente. Sem o seu empenho e conhecimento da realidade circundante, a troca perde seu efeito subversivo de continuidade, tornando-se 
meramente um acontecimento esporádico e de enfeite. Em colaboração com os atores que têm uma experiência dramatúrgica, esses indivíduos anônimos e profundamente motivados são capazes de sacudir a dinâmica de seu meio ao deflagrar um processo de iniciativas transversais. Nesse processo preparatório está a semente de um re-pensamento do teatro pelas mesmas pessoas que nunca antes haviam sentido a necessidade dele.

Re-pensar o teatro significa estar consciente do seu poder de interferência criativa, de seu efeito revitalizante, ainda que perturbador. O Odin Teatret tem realizado trocas em escolas e hospitais psiquiátricos, prisões e quartéis militares em cidades com toques de recolher, bairros difíceis e igrejas meio vazias (que encheram durante a troca), em clubes desportivos e museus elitistas, com párias burakumin no Japão e com a tribo Yanomami na Amazônia.

Eugenio Barba contou-me como o xamã Yanomami lhe deu a melhor definição de permuta. O xamã estava escutando Eugenio, enquanto ele tentava explicar o que o Odin Teatret iria fazer e o que esperávamos de sua tribo. De repente, seu rosto se iluminou e ele interrompeu: "Ah, você quer trocar energia!" O mecanismo de troca não é mecânico. Ele depende do equilíbrio vulnerável da confiança mútua.

Um exemplo concreto vem da Holstebro Festuge de 2014. Seu título é "Rostos do futuro Ficções (as promessas de nossos políticos) e Fantasmas (do passado: racismo, violência contra mulheres e crianças, pedofilia e incesto)." Imaginando diferentes rostos do futuro, o Odin Teatret convidou grupos de crianças e jovens artistas, músicos e acrobatas de Bali, Quênia, Brasil e Europa, entre outros, mais de uma centena ao todo. Atores do Odin já haviam trabaIhado com os professores e alunos de escolas primárias locais por muitos anos. Nós sabíamos quais diretores de escola estavam abertos a novas iniciativas e ansiosos para melhorar a participação coletiva da sua escola. Nossos atores propuseram aos líderes escolares que preparassem uma série de atividades com pais e alunos durante o ano escolar precedente à Festuge, e que trocassem os resultados com um grupo de jovens estrangeiros convidados. Mas eles também deveriam fornecer hospitalidade na forma de alimentação, alojamento e transporte local. Acima de tudo, eles deveriam estabelecer uma fusão entre seus estudantes e os convidados estrangeiros, a fim de planejar e concretizar uma série de iniciativas em seu território circundante. Cabe a eles criar o programa para a Festuge em suas áreas com espetáculos, concertos, eventos esportivos, jogos, visitas a cidadãos no seu bairro para agradecê-los 
por uma contribuição especial ou para comemorar um aniversário; convidar lares de idosos, ou marchas para invadir festivamente uma igreja, um jardim de infância ou um banco que thes tenha patrocinado. Várias escolas nas aldeias fora de Holstebro aceitaram.

Cultura em nossas próprias mãos poderia ser o slogan para a forma como o Odin Teatret motiva essas escolas a participarem, tanto financeiramente como com os seus recursos humanos. Os diretores das escolas sabem que a Municipalidade de Holstebro não pode organizar e subsidiar entretenimento cultural ou experiências artísticas em suas pequenas localidades. Portanto, eles ficam ansiosos para participar com as suas próprias iniciativas, tanto para estimular a energia do seu meio como para reforçar a sua coesão. Alunos, professores e pais se misturam em um processo criativo compartilhado, que também se abre para os estrangeiros. Eles desejam enfatizar o espírito de cordialidade e inventividade de sua comunidade, um pouco esquecido, estabelecendo laços com outras escolas que vivem sob uma ameaça semelhante de fechamento pelo município que as considera muito pequenas, velhas e ultrapassadas.

Uma comunidade consiste em uma grade complexo de relações. Diferentes trabalhos, especializações, instituições e associações são microculturas, cada uma estruturada de acordo com relações particulares que servem a seus objetivos específicos próprios. Há uma variedade de subculturas em uma cidade: delegacias de polícia e igrejas, clubes desportivos e instituições culturais, organizações de base, fábricas e lojas, escritórios municipais e sindicatos, teatros, escolas, associações étnicas e políticas, museus, bandas e orquestras... Essas parcerias são o DNA do corpo vivo de qualquer cidade. Mas elas operam desconectadas entre si, no âmbito limitado de suas próprias condições de trabalho, atividade especializada e vida privada. Estranhamento e exclusão se tornam tendências evidentes quando interesses étnicos, geracionais, de gênero, de classe, de educação, de raça e regionais se transformam em indiferença mútua e confronto.

Portanto o principal compromisso da Festuge de Holstebro é encontrar estratagemas e benefícios mútuos para motivar e aproximar pessoas e ambientes que parecem destinados a nunca se encontrarem. Sua execução descentralizada é transformadora, buscando modificar idéias preconcebidas. Também é interativa porque encarna a essência do teatro, que está enraizada no contato vivo. A Festuge de Holstebro tem agora um capital sólido e tradição: a habilidade para tecer contatos entre as várias camadas da população. Cada Festuge gera um 
renovado processo de negociação e de construção de pontes. Novas ideias e procedimentos comprovados devem ser convertidos em energia utilizável para inspirar e levar a relacionamentos impensáveis, porém efetivos.

Michael Böss da Universidade de Aarhus, diz em uma entrevista: “A democracia é também uma questão de como o cidadão individual se sente envolvido na sociedade. Neste sentido, a Festuge tem ajudado a fortalecer a democracia de base. É fantástico ter várias organizações e instituições considerando-se parte de um todo maior. Uma vez que o Odin Teatret não apresenta uma 'dinamarquesidade' no sentido tradicional, mas uma alteridade, é interessante que esse teatro particular contribua para a criação de uma cidadania mais inclusiva. Acredito que muitos sentem que o teatro contribui para criar e dar uma identidade para a cidade. Tal identidade tem um poder mobilizador quando uma pessoa de repente experimenta uma espécie de comunhão urbana combinada a um elevado grau de comunicação e orgulho da própria cidade. Este orgulho é alegria e também empenho".

Re-pensar o teatro abre-se à prática de relacionar-se com o que é diferente, dando-lhe uma dramaturgia e tornando-o visível através de empatia, intercâmbio e de um contato direto estruturado. É isso que o Odin Teatret se esforça para alcançar, dando estrutura artística a intermináveis matizes culturais de sua comunidade e virando as regras de ponta-cabeça através de uma visão que modifica a realidade durante os nove dias e noites da Holstebro Festuge. 